\title{
Effect of electroacupuncture stimulation at Zusanli acupoint (ST36) on gastric motility: possible through PKC and MAPK signal transduction pathways
}

Qi Yang ${ }^{1 \dagger}$, Yan-Dong Xie ${ }^{1 \dagger}$, Ming-xin Zhang ${ }^{1}$, Bo Huang ${ }^{2}$, Chao Zhang ${ }^{1}$, Hui-Yan Li ${ }^{1}$, Rong Zhang ${ }^{1}$, Ming Qin ${ }^{1}$, Yu-Xin Huang ${ }^{1}$ and Jing-Jie Wang ${ }^{1 *}$

\begin{abstract}
Background: Electroacupuncture (EA) stimulation has been shown to have a great therapeutic potential for treating gastrointestinal motility disorders. However, no evidence has clarified the mechanisms contributing to the effects of EA stimulation at the Zusanli acupoint (ST.36). This study was designed to investigate the regulative effect of EA stimulation at the ST.36 on gastric motility and to explore its possible mechanisms.

Methods: Thirty Sprague-Dawley rats were randomly divided into three groups: the ST.36 group, the non-acupoint group, and the control group. EA stimulation was set at $2 \mathrm{~Hz}$, continuous mode, and $1 \mathrm{~V}$ for $30 \mathrm{~min}$. The frequency and average peak amplitude of gastric motility were measured by electrogastrography. The protein kinase C (PKC) and mitogen-activated protein kinase (MAPK) signaling pathways were assessed using real-time polymerase chain reactions. Caldesmon (CaD) and calponin (CaP) protein expression in the gastric antrum were detected on Western blots. A Computed Video Processing System was used to evaluate morphological changes in smooth muscle cells (SMCs) from the gastric antrum.

Results: EA stimulation at ST.36 had a dual effect on the frequency and average peak amplitude. Additionally, EA stimulation at ST.36 regulated the expression of some genes in the PKC and MAPK signaling pathways, and it regulated the expression of the $\mathrm{CaD}$ and $\mathrm{CaP}$ proteins. EA serum induced SMC contractility. Promotion of gastric motility may correlate with up-regulation of MAPK6 (ERK3), MAPK13, and Prostaglandin-endoperoxide synthase 2 (PTGS2) gene expression, and the down-regulation of the collagen, type I, alpha 1 (COL1A1) gene and CaD and CaP protein expression. Inhibition of gastric motility may correlate with down-regulation of the Interleukin-1 receptor type 2 (IL1R2) and Matrix metalloproteinase-9 (MMP9) genes, and up-regulation of CaD and CaP protein expression.
\end{abstract}

Conclusions: EA stimulation at ST.36 regulated gastric motility, and the effects were both promoting and inhibiting in rats. The possible mechanisms may correlate with the PKC and MAPK signal transduction pathways.

Keywords: Electroacupuncture, Zusanli, Gastric motility, PKC, MAPK

\footnotetext{
* Correspondence: jingjie@fmmu.edu.cn

${ }^{\dagger}$ Equal contributors

'Department of Gastroenterology, Tangdu Hospital of the Forth Military

Medical University, Xi'an, Shanxi 710038, China

Full list of author information is available at the end of the article
} 


\section{Background}

Gastric motility is one of the most critical physiological functions of the human gut. Without coordinated motility, the digestion and absorption of dietary nutrients cannot take place. The regulation of gastrointestinal motility is complicated and involves the contraction of smooth muscle cells (SMCs). The contraction of SMCs is primarily regulated by transient changes in the intracellular $\mathrm{Ca}^{2+}$ concentration [1]. There are two major pathways involved in this mechanism, namely, the RhoA-Rho kinase pathway and the protein kinase $\mathrm{C}$ (PKC) pathway [2]. Calponin ( $\mathrm{CaP})$, a well established in vitro substrate for signaling proteins by PKC [3], directly interacts with PKC [4]. Caldesmon $(\mathrm{CaD})$ is an actin and myosin binding protein that exists in two isoforms, which are generated by alternative splicing [5]. There is accumulating evidence for a secondary pathway in the regulation of smooth muscle contraction that is PKC dependent, and this pathway may be mediated by $\mathrm{CaP}$ and $\mathrm{CaD}$ activation [6-9]. Mitogen-activated protein kinase (MAPK) signaling pathways have also been implicated in SMC contraction [10]. There are three major groups of distinctly regulated MAPKs that lead to altered gene expression. The extracellular signal related kinases 1 and 2 (ERK1/2), the C-jun terminal kinase (JNK), and the p38 MAPK are known to play important roles in the intracellular signaling response to extracellular stimuli [11]. In addition, CaP may facilitate ERKdependent signaling, thus playing a significant role in the regulation of SMC contraction [12].

Acupuncture, which has been used for thousands of years in China, is increasingly used worldwide for the management of various diseases [13]. It is believed that stimulation of an acupoint can directly affect relevant organs and achieve the effect of acupuncture therapy. EA is a combined procedure that stimulates an acupoint with electrical stimulation instead of with manual manipulations of needles. Numerous studies have evaluated the effects and mechanisms of EA on gastric motility [14-20]. Based on the evidence from these studies, EA stimulation has been shown to have a great therapeutic potential for treating gastrointestinal motility disorders. The Zusanli (ST.36) is one of the most commonly used acupoints for gastrointestinal diseases. According to the theory of Traditional Chinese Medicine (TCM), there is a relationship between ST.36 and the function of the gastrointestinal tract. To date, however, no evidence has clarified the exact mechanisms contributing to the effects of EA stimulation.

Therefore, by examining morphologic changes and myoelectrical activity, the present study aimed to evaluate the regulative effect of EA stimulation at the ST.36 acupoint on gastric motility in rats and to explore its possible mechanisms.

\section{Methods}

\section{Animals and reagents}

Thirty adult male Sprague-Dawley (SD) rats weighing 180-220 g were maintained on a 12-h light-dark cycle at $25 \pm 2{ }^{\circ} \mathrm{C}$ and $60 \%$ humidity with free access to food and water. SD rats were purchased from the Experimental Animal Center of the Fourth Military Medical University. All animal experiments were carried out in accordance with the institutional guidelines of the Fourth Military Medical University for the care and use of laboratory animals. Approval of the study protocol was obtained from the Ethics Committee for Animal Research, Fourth Military Medical University, China. Animals were randomly allocated into three groups: the ST.36 group, the non-acupoint group, and the control group.

Collagenase II, trypsin inhibitor, dithiothreitol alcohol sugar, bovine serum albumin, calcium-free phosphate buffered saline (PBS), glutaraldehyde, and Trypan blue were purchased from Sigma Chemical Co. The Total RNA Extraction Kit, SuperScript III Reverse Transcriptase, and SuperArray PCR Master Mix were purchased from Invitrogen Co. Anti-goat, anti-mouse, and anti-rabbit antibodies were purchased from Shanghai Kangcheng BioEngineering Co.

\section{EA stimulation procedure}

The ST.36 was located approximately $5 \mathrm{~mm}$ lateral to the fibula of the hind limbs, while the non-acupoint was located on the hind foot next to the ST.36 open $5 \mathrm{~mm}$ [21]. The needles were inserted $5 \mathrm{~mm}$ deep into the muscle layer of the selected acupoint and were stimulated by EA at $2 \mathrm{~Hz}$ and $2 \mathrm{~V}$ using an electrical stimulator (G6805-2A; Shanghai Huayi Medical Instrument Factory, Shanghai, China). Each stimulation lasted $20 \mathrm{~min}$ in continuous mode, and stimulation was carried out 1 time/day for 5 days. The rats in control group were submitted to immobilization alone without stimulation for $30 \mathrm{~min}$ at the same time each day.

\section{Electrogastrography}

Electrogastrography was applied using the Multichannel Physiologic Signal Acquisition and Processing System (mode RM-6280) after the last stimulation on the fifth day. Following a 12-h fast (with free access to water) and $6 \mathrm{~h}$ without drink, the rats were anesthetized intraperitoneally (i.p.) with $10 \%$ urethane at a dose of $1 \mathrm{~g} / \mathrm{kg}$ body and then immobilized. The first electrode was fixed to the tail, and guided electrodes were implanted on the serosal surface of the stomach $0.3-0.5 \mathrm{~cm}$ above the pylorus. The electrodes were covered with $37^{\circ} \mathrm{C}$ normal saline gauze, connected with wire. The experimental parameters used were as follows: frequency $400 \mathrm{~Hz}$, filter $10 \mathrm{~Hz}$, scanning speed $2 \mathrm{~s} /$ division, sensitivity $25 \mathrm{mV}$, 
time constant direct current, and oscilloscope recording time $1 \mathrm{~h} \mathrm{[18].}$

\section{Real-time polymerase chain reaction (PCR) analysis}

After the last stimulation with EA, the rats were sacrificed. For control group and non-acupoint group, one rat was randomly selected respectively. For EA group, we first divided it into EA promoting group and EA inhibiting group according to the results of the electrogastrography. And then, there rats were randomly selected from both groups. Gastric antrum tissues (from the pyloric $0.8-1 \mathrm{~cm}$ ) were cut into pieces that were approximately $0.3 \mathrm{~cm} \times 0.5 \mathrm{~cm}$ in size and immediately placed in $-70^{\circ} \mathrm{C}$ liquid nitrogen. Total RNA samples were extracted using TRIZOL from different groups according to the manufacturer's instructions. RNA quality was assessed spectrophotometrically on the basis of the A260/A280 ratio. RNA samples were checked for integrity of the $18 \mathrm{~S}$ and $28 \mathrm{~S}$ RNA by gel electrophoresis. Total RNA $(1.5 \mu \mathrm{g})$ was used to generate first-strand cDNA with SuperScript III Reverse Transcriptase $(1 \mu \mathrm{l})$ from the isolated RNA. The real-time PCR reactions were prepared using a SuperArray PCR Master Mix (Cat. No. PA-112) containing the PKC and MAPK signal pathway genes. The diluted cDNA $(102 \mu \mathrm{l})$ was added to each hole corresponding to the PCR chip. Then the PCR chips were placed into the real-time PCR instrument for the PCR reaction. The cycling conditions were as follows: $95^{\circ} \mathrm{C}$ for $10 \mathrm{~min}, 60^{\circ} \mathrm{C}$ for $15 \mathrm{~s}$, and $60^{\circ} \mathrm{C}$ for $1 \mathrm{~min}$ (40 cycles). Differences in gene expression, expressed as fold-changes, were calculated using the $2^{-\Delta \Delta \mathrm{Ct}}$ method.

\section{Western blots of $\mathrm{CaD}$ and $\mathrm{CaP}$}

The $\mathrm{CaD}$ and $\mathrm{CaP}$ protein levels were detected by Western blotting. After treatment with EA, the rats were sacrificed. The rats were then fixed, followed by incision of the abdominal skin and peritoneum. The viscera were exposed, and the central $1 / 3$ of the gastric body was cut into small pieces that were approximately $0.3 \mathrm{~cm} \times$ $0.5 \mathrm{~cm}$ in size. The pieces were immediately stored at $-70^{\circ} \mathrm{C}$ in liquid nitrogen. Briefly, cell extracts $(30 \mu \mathrm{g})$ from the upper $1 / 3$ of the middle of the gastric body were separated by sodium dodecyl sulfate-polyacrylamide gel electrophoresis (SDS-PAGE) and then transferred to nitrocellulose membranes. The filters were blocked with Tris-buffered saline (TBS)/5\% milk, followed by incubation with polyclonal antibodies against $\mathrm{CaD}(1: 3000 \mathrm{di}$ lution), $\mathrm{CaP}$ (1:3000 dilution), and $\beta$-actin (1:10000). After the membranes were washed, they were incubated with secondary peroxidase-conjugated antibodies diluted 1:5000 in TBS with $0.01 \%$ Tween 20 . The antibody detection system was used, and the membranes were exposed to X-ray film according to the manufacturer's instructions.

\section{Serum preparation}

Serum was prepared as previously described with modification [22]. After the last stimulation with EA, all rats were sacrificed. Next, $6 \mathrm{ml}$ of blood was taken from the carotid of each rat. The blood was kept still for $1 \mathrm{~h}$, and then centrifuged at $3000 \mathrm{rpm}$ for $15 \mathrm{~min}$. The serum was collected, filtered to remove bacteria, and $1.5 \mathrm{ml}$ was packed in an EP tube, which was stored at $-70^{\circ} \mathrm{C}$ in liquid nitrogen.

\section{Effects of EA serum on SMC contractility}

Five normal SD rats were anesthetized i.p. with $10 \%$ urethane at a dose of $1 \mathrm{~g} / \mathrm{kg}$ body weight. After being anesthetized, the abdominal skin and peritoneum were incised, and the viscera were exposed. The whole stomach was cut out, and the gastric antrum tissues were isolated and immediately placed in oxygen saturated PBS with penicillin $(100 \mathrm{U} / \mathrm{ml})$ and streptomycin $(100 \mu \mathrm{g} / \mathrm{ml})$ at $4^{\circ} \mathrm{C}$. After being rinsed, the tissues were transferred to oxygen saturated HEPES, spread and fixed on a silica gel plate with a fine-needle. The mucosal layer was carefully cut off, exposing the circular mucosa, which was clipped into 9-10 muscle strips $(1 \mathrm{~mm} \times 4 \mathrm{~mm})$, placed in Tyrode's solution, and kept at $4{ }^{\circ} \mathrm{C}$ in the refrigerator for approximately $15 \mathrm{~min}$. The muscle strips were digested in $1 \%$ collagenase type II, $0.05 \%$ trypsin inhibitor, $0.05 \%$ dithiothreitol alcohol sugar, and $0.2 \%$ bovine serum albumin enzyme in a water bath for $25 \mathrm{~min}$ at $36^{\circ} \mathrm{C}$. After digestion, the mixture was rinsed with enzyme-free HEPES, incubated for $30 \mathrm{~min}$, and filtered with a 200 screen mesh to collect the free single gastric SMCs. Cell viability was measured with the Trypan blue test. The living cells were more than $95 \%$ at a density of $10^{6}$ cells $/ \mathrm{ml}$.

The isolated SMCs were randomly divided into the normal serum group, ST.36 serum group, and nonacupoint serum group. SMCs suspensions $(50 \mu \mathrm{l})$ at a density of $1.0 \times 10^{6}$ cells $/ \mathrm{ml}$ were placed in 96-well plates. Each serum sample was inactivated after $30 \mathrm{~min}$ in a $56^{\circ} \mathrm{C}$ water bath, and then diluted 1:2 with HEPES. Serum $(50 \mu \mathrm{l})$ from the different groups was added to SMCs, mixed with a pipette for $30 \mathrm{~s}$, and fixed with $30 \mu \mathrm{l} 2.5 \%$ glutaraldehyde. Cell length was assessed with a Computed Video Processing System (DP2-BSW), which was used to calculate the shrinkage percentage. The cell shrinkage percentage $=$ (cell length before treatment - cell length after treatment)/cell length before treatment $\times 100 \%$.

\section{Statistical analysis}

Data were expressed as mean \pm S.D. One-way analysis of variance followed by Bonferroni's multiple comparison test was applied with SPSS 10.0 software. The $\Delta \mathrm{Ct}$ values obtained from the real-time $\mathrm{PCR}$, which were used to calculate the fold-change differences (expressed 
Table 1 Gene change comparing EA promoting group with control group

\begin{tabular}{lllll}
\hline Signal pathway & Gene & Sites & $\begin{array}{l}\text { EA/control } \\
\text { (Fold change) }\end{array}$ & $\begin{array}{l}\text { EA/control } \\
\text { (Fold up- or down-regulation) }\end{array}$ \\
\hline MAPK & MAPK6 (ERK3) & D02 & 2.39 & 2.39 \\
MAPK & MAPK13 & D10 & 2.86 & 2.86 \\
PKC & IL1R1 & F08 & 2.18 & 2.18 \\
PKC & PRKCA & G01 & 2.40 & 2.40 \\
PKC & PTGS2 & G02 & 2.72 & 2.72 \\
PKC & IL1R2 & F09 & 0.26 & -3.85 \\
\hline
\end{tabular}

Fold-change $\left(2^{-\Delta \Delta \mathrm{Ct}}\right)$ is the normalized gene expression $\left(2^{-\Delta \mathrm{Ct}}\right)$ in the test sample divided by the normalized gene expression $\left(2^{-\Delta \mathrm{Ct}}\right)$ in the control sample. Foldregulation represents the fold-change results in a biologically meaningful way. Fold-change values greater than one indicate a positive- or up-regulation, and the fold-regulation is equal to the fold-change. Fold-change values less than one indicate a negative or down-regulation, and the fold-regulation is the negative inverse of the fold-change.

here as percent of control), were also used for the statistical analysis. A $p$-value $<0.05$ or a fold-change $>2$ was defined as statistically significant for all analyses.

\section{Results}

\section{Effects of EA on gastric motility}

EA at ST.36 produced significant changes in the absolute value of the average peak amplitude and frequency compared with the control or non-acupoint groups $(P<$ $0.01)$. In contrast, EA at the non-acupoint did not induce significant changes in gastric motility compared with the control group (Additional file 1: Figure S1). Two types of gastric motor patterns were observed for the ST.36 group in the 10 rats tested according the average peak: rats with positive average peak were judged to promoting pattern, while rats with negative average peak were judged to promoting pattern. The results showed 5 (50.0\%) rats showed the ST.36 promoting pattern and 5 (50.0\%) rats showed the ST.36 inhibiting pattern. In rats with the ST.36 promoting pattern, the average peak amplitude and frequency values were $47.13 \pm 0.44$ and $0.19 \pm 0.06$, respectively. In rats with the ST.36 inhibiting pattern, the average peak amplitude and frequency values were $-43.41 \pm 0.62$ and $0.17 \pm 0.03$, respectively (Additional file 2: Table S1).

\section{Effects of EA on the PKC and MAPK signaling pathways}

EA at ST.36 significantly regulated the expression of some genes in the PKC and MAPK signaling pathways. Table 1 lists the results from the microarray analysis of the ST.36 promoting group (as compared to the control group). The expression of many genes was increased after EA stimulation, including ERK3, MAPK13, IL1R1, PRKCA, and PTGS2. Other genes showed decreased expression after EA stimulation, including IL1R2. Table 2 lists the results from the microarray analysis of the ST.36 inhibiting group (as compared to the control group). The gene expression of IL1R2 and MMP9 were decreased after EA stimulation.

Table 3 lists the results from the microarray analysis of the ST.36 promoting group (as compared to the nonacupoint group). The expression of the COL1A1 gene was increased after EA stimulation. The expression of the IL1R2 and SERPINE1 genes were decreased after EA stimulation. Table 4 lists results from the microarray analysis of the ST.36 inhibiting group (as compared to the non-acupoint group). Many of the genes showed decreased expression after EA stimulation, including the ERK3, JNK3, p38bMAPK, MAPK13, p38MAPK, ERK1, FGF2, IL1R1, IL1R2, MYC, PRKCA, and PTGS2 genes. The expression of the COL1A1 gene was increased after EA stimulation.

\section{Effects of $\mathrm{EA}$ on $\mathrm{CaD}$ and $\mathrm{CaP}$ protein expression}

Stimulation with EA significantly increased $\mathrm{CaD}$ and $\mathrm{CaP}$ protein expression in the ST.36 inhibiting group compared with the non-acupoint group, whereas stimulation with EA significantly decreased $\mathrm{CaD}$ and $\mathrm{CaP}$ protein expression in ST.36 promoting group compared with the non-acupoint group (Figure 1A, B, C, D).

Table 2 Gene change comparing EA inhibitory group with control group

\begin{tabular}{|c|c|c|c|c|}
\hline Signal pathway & Gene & Sites & $\begin{array}{l}\text { EA/control } \\
\text { (Fold change) }\end{array}$ & $\begin{array}{l}\text { EA/control } \\
\text { (Fold up- or down-regulation) }\end{array}$ \\
\hline PKC & IL1R2 & F09 & 0.24 & -4.26 \\
\hline PKC & MMP9 & F11 & 0.21 & -4.68 \\
\hline
\end{tabular}

Fold-change $\left(2^{-\Delta \Delta \mathrm{Ct}}\right)$ is the normalized gene expression $\left(2^{-\Delta \mathrm{Ct}}\right)$ in the test sample divided by the normalized gene expression ( $\left.2^{-\Delta \mathrm{Ct}}\right)$ in the control sample. Foldregulation represents the fold-change results in a biologically meaningful way. Fold-change values greater than one indicate a positive- or up-regulation, and the fold-regulation is equal to the fold-change. Fold-change values less than one indicate a negative or down-regulation, and the fold-regulation is the negative inverse of the fold-change. 
Table 3 Gene change comparing EA promoting group with non-acupoint group

\begin{tabular}{lllll}
\hline Signal pathway & Gene & Sites & $\begin{array}{l}\text { EA/Non-acupoint } \\
\text { (Fold change) }\end{array}$ & $\begin{array}{l}\text { EA/Non-acupoint } \\
\text { (Fold up- or down-regulation) }\end{array}$ \\
\hline PKC & COL1A1 & F05 & 3.60 & 3.60 \\
PKC & IL1R2 & F09 & 0.39 & -2.54 \\
PKC & SERPINE1 & G04 & 0.48 & -2.07 \\
\hline
\end{tabular}

Fold-change $\left(2^{-\Delta \Delta \mathrm{Ct}}\right)$ is the normalized gene expression $\left(2^{-\Delta \mathrm{Ct}}\right)$ in the test sample divided by the normalized gene expression ( $\left.2^{-\Delta \mathrm{Ct}}\right)$ in the control sample. Foldregulation represents the fold-change results in a biologically meaningful way. Fold-change values greater than one indicate a positive- or up-regulation, and the fold-regulation is equal to the fold-change. Fold-change values less than one indicate a negative or down-regulation, and the fold-regulation is the negative inverse of the fold-change.

\section{Effects of EA serum on SMC contractility}

As shown in Additional file 3: Figure S2 and Additional file 4: Table S2, cell morphology was observed under the light microscope after treatment with different types of serum. There were no differences in cell length before the addition of serum $(\mathrm{p}>0.05)$. ST.36 serum increased SMC contractility $(60.22 \pm 3.84 \mu \mathrm{m})$ compared with the control serum $(96.02 \pm 6.24 \mu \mathrm{m})$ or the non-acupoint serum $(97.33 \pm 6.97 \mu \mathrm{m})$. The contraction percentage was $41 \%$ after stimulation with ST.36 serum, whereas the contraction percentages were $7 \%$ and $10 \%$ after stimulation with either the non-acupoint serum or control serum, respectively.

\section{Discussion}

The present study demonstrated that EA stimulation at ST.36 had a regulative effect on gastric motility in rats that was either stimulatory or inhibitory. The stimulating effect of EA may act through the PKC and MAPK signaling pathways.
The effects of EA on gastric motility have been extensively studied in both animals and humans due to the availability of electrogastrography. It is well known that gastric myoelectrical activity consists of slow waves and spikes. Spikes are directly associated with the appearance of contractions. Slow waves do not evoke gastrointestinal contractility, but they determine the maximum frequency of gastric contractions.

The most often used acupoint in treating gastrointestinal disorders is the ST.36. It is commonly believed that acupuncture may exert promoting and inhibiting effects on gastrointestinal motility depending on the stimulated acupoint. In humans, it has been shown that EA stimulation at ST.36 had dual effects on gastric peristalsis that are either facilitative or inhibitory [15,23]. Although patients suffering from gastrointestinal diseases have benefited from the application of acupuncture at ST.36, but the exact molecular mechanisms are still unclear. In dogs, EA at ST.36 increased the regularity of gastric slow waves $[24,25]$. In conscious rats, EA stimulation at ST.36

Table 4 Gene change comparing EA inhibitory group with non-acupoint group

\begin{tabular}{|c|c|c|c|c|}
\hline Signal pathway & Gene & Sites & $\begin{array}{l}\text { EA/Non-acupoint } \\
\text { (Fold change) }\end{array}$ & $\begin{array}{l}\text { EA/Non-acupoint } \\
\text { (Fold up- or down-regulation) }\end{array}$ \\
\hline MAPK & MAPK6 (ERK3) & D02 & 0.18 & -5.67 \\
\hline MAPK & MAPK10 (JNK3) & D07 & 0.42 & -2.40 \\
\hline MAPK & MAPK11 (p38bMAPK) & D08 & 0.39 & -2.58 \\
\hline MAPK & MAPK13 & D10 & 0.28 & -3.58 \\
\hline MAPK & MAPK3 (ERK1) & G11 & 0.26 & -3.83 \\
\hline MAPK & MAPK14 (p38MAPK) & D11 & 0.47 & -2.13 \\
\hline PKC & FGF2 & F07 & 0.37 & -2.67 \\
\hline PKC & IL1R1 & F08 & 0.30 & -3.31 \\
\hline PKC & IL1R2 & F09 & 0.36 & -2.81 \\
\hline PKC & MMP9 & F11 & 0.22 & -4.48 \\
\hline PKC & MYC & $\mathrm{F} 12$ & 0.39 & -2.59 \\
\hline PKC & PRKCA & G01 & 0.23 & -4.27 \\
\hline PKC & PTGS2 & G02 & 0.19 & -5.36 \\
\hline PKC & COL1A1 & F05 & 4.81 & 4.81 \\
\hline
\end{tabular}

Fold-change $\left(2^{-\Delta \Delta \mathrm{Ct}}\right)$ is the normalized gene expression $\left(2^{-\Delta \mathrm{Ct}}\right)$ in the test sample divided by the normalized gene expression ( $\left.2^{-\Delta \mathrm{Ct}}\right)$ in the control sample. Foldregulation represents the fold-change results in a biologically meaningful way. Fold-change values greater than one indicate a positive- or up-regulation, and the fold-regulation is equal to the fold-change. Fold-change values less than one indicate a negative or down-regulation, and the fold-regulation is the negative inverse of the fold-change. 


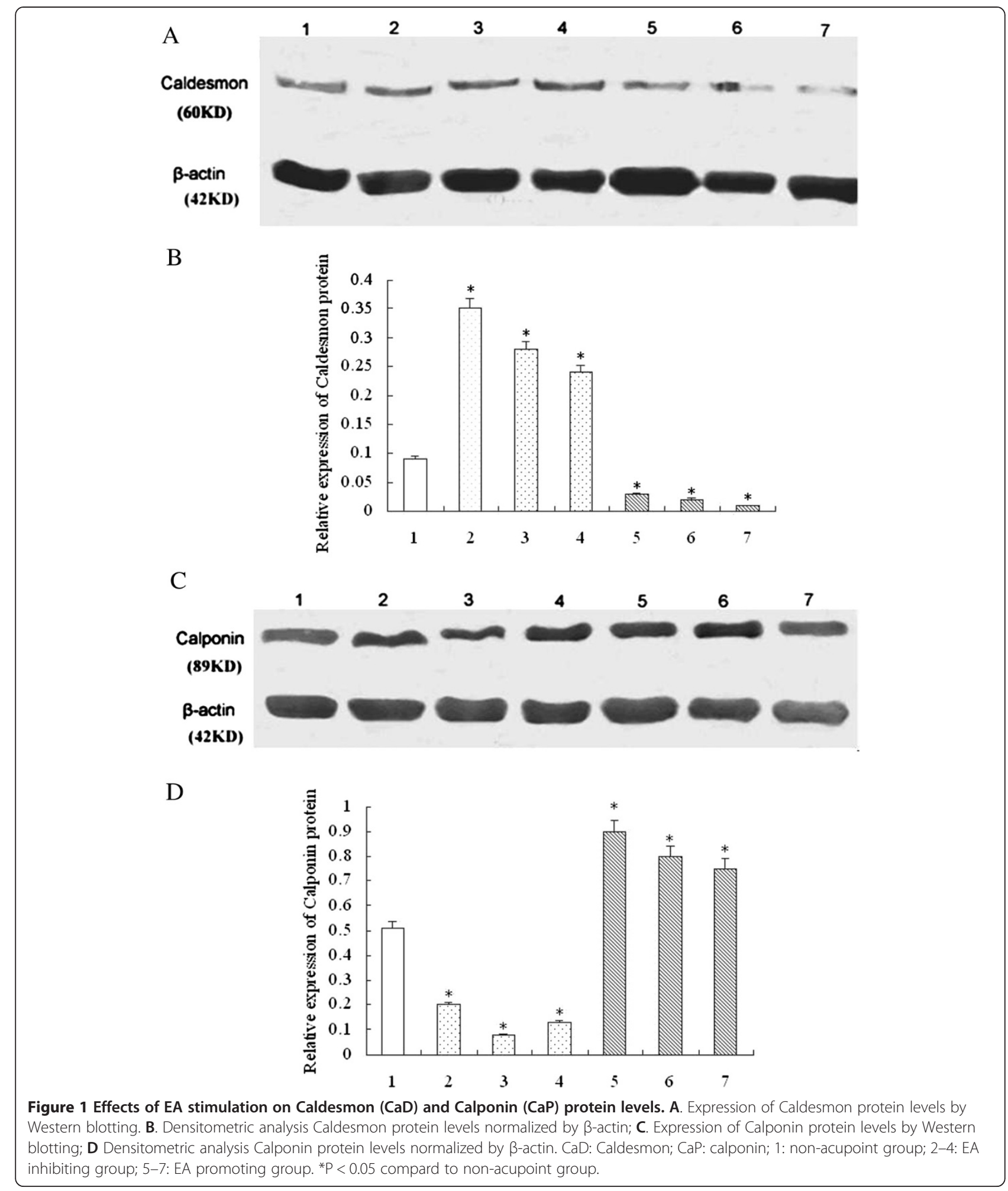

induced dual effects, which were either facilitative or inhibitory, on gastric motility [26,27]. Further study revealed that the stimulatory effect is mediated via cholinergic pathways, while the inhibitory effect is independent of the sympathetic pathway [28]. The general theory of acupuncture medicine is premised on the concept of Yin and Yang, and acupuncture is believed to modify the imbalance between Yin and Yang. The effects 
of acupuncture on balancing Yin and Yang may be mediated via the interaction between the neurotransmission of GABA and glutamate in the brain stem.

In the current paper, EA stimulation at ST.36 was effective in regulating gastric motility, as demonstrated by the significant increase in peak amplitude and frequency. In addition, the lack of such a response when the same stimulation was performed at the non-acupoint was indicative of the specificity of this effect. According to the peak amplitude and frequency, the ST.36 group was further divided into promoting and inhibitory patterns, since EA showed a dual effect. To further explore the mechanisms by which EA regulates gastric motility, we isolated SMCs from the stomach and observed the effect of ST.36 serum on SMC contractility using serologic pharmacological testing methods. The results showed that ST.36 serum significantly increased SMC contractility; whereas the effects produced by normal or nonacupoint serum were not obvious.

Recent investigations suggested that the effects of EA stimulation are mediated through the opioid system [29] or through its stimulating effect on vagal activity [30]; however, the precise mechanisms by which EA affects gastric motility were not fully understood. Previous findings also indicated that PKC levels were increased after stimulation with EA [31]. Therefore, we selected the PKC and MAPK pathways as targets for mediating the stimulatory effects of EA on gastric mobility. Moreover, $\mathrm{CaP}$ and $\mathrm{CaD}$ may play a role in the regulation of gastrointestinal motility during physiological and pathological adaptation. Up-regulation of $\mathrm{CaP}$ and $\mathrm{CaD}$ expression inhibited gastrointestinal motility, and down-regulation of $\mathrm{CaP}$ and $\mathrm{CaD}$ expression promoted gastrointestinal motility [32,33]. ERK1/2, a member of the MAPK family, has been shown to play a significant role in the regulation of smooth muscle contraction [34]. According to our microarray results, promotion of gastric motility may correlate with up-regulation of MAPK6 (ERK3), MAPK13, and PTGS2 gene expression, and downregulation of COL1A1 gene expression. Inhibition of gastric motility may correlate with down-regulation of IL1R2 and MMP9 gene expression. Western blots showed up-regulation of $\mathrm{CaD}$ and $\mathrm{CaP}$ protein expression inhibited gastric motility, whereas down-regulation of $\mathrm{CaD}$ and $\mathrm{CaP}$ protein expression promoted gastric motility. These results demonstrate that $\mathrm{CaD}$ and $\mathrm{CaP}$ may play a role in the regulation of gastrointestinal motility during physiological and pathological adaptation.

There were some limitations in the present study that should be mentioned. First, we did not investigate whether the inhibitors of PKC and MAPK could affect or block the regulatory effect of EA stimulation at ST.36 on gastric mobility. Further studies will be required to investigate the influences of PKC and MAPK inhibitors.
Second, future investigations will focus on fully understanding the roles of each change in gene expression upon the regulation of gastric mobility.

\section{Conclusions}

In summary, our findings demonstrate that EA stimulation at ST.36 regulated gastric motility. EA stimulation at ST.36 exerted dual effects on gastric motility that were either stimulatory or inhibitory. In addition, regulation of gastric motility may correlate with the PKC and MAPK signal transduction pathways.

\section{Additional files}

\begin{abstract}
Additional file 1: Figure S1. Effects of EA stimulation on gastric motility. Gastric motility was measured by electrogastrography. A. Control, B. ST.36, C. Non-acupoint. Stimulation with EA at ST.36 increased the average peak amplitude and frequency. Gastric waves showed dual changes in the ST.36 group compared with the control or non-acupoint group. Values are expressed as the mean \pm S.D. $(n=10) .{ }^{*} p<0.05,{ }^{* *} p<0.01$ vs. control group. ${ }^{\#} p<0.05,{ }^{\#} p<0.01$ vs. non-acupoint group.

Additional file 2: Table S1. Effects of EA on gastric myoelectrical activity. The ST.36 group was further divided into EA promoting and EA inhibiting groups according to the gastric waves. Values are expressed as mean \pm S.D $(n=5)$

Additional file 3: Figure S2. Effects of EA stimulation on gastric SMC contractility. Cell morphology was observed using a light microscope ( $\times 200$ magnification). The length of the cell and the contraction percentage was measured with a Computer Image Analysis System. O. SMCs; A. SMCs + control serum; B. SMCs + ST.36 serum; C. SMCs + non-acupoint serum

Additional file 4: Table S2. Effects of serum on SMC contractility. As assessed by the Computed Video Processing System, Zusanli serum resulted in significant contractility in SMCs. Results are expressed as the mean \pm S.D $(n=10) .{ }^{*} p<0.05{ }^{* *} p<0.01$ vs. control serum group. ${ }^{\#} p<0.05,{ }^{\#} p<0.01$ vs. non-acupoint serum.
\end{abstract}

Competing interests

The authors declare that they have no competing interests.

\section{Authors' contributions}

QY carried out the molecular genetic studies, participated in the sequence alignment and drafted the manuscript. YDX, MXZ, BH carried out the immunoassays. CZ, HYLi, RZ participated in the sequence alignment. MQ, YXH participated in the design of the study and performed the statistical analysis. JJW conceived of the study, and participated in its design and coordination and helped to draft the manuscript. All authors read and approved the final manuscript.

\section{Acknowledgements}

This study was supported by grants from the National Natural Science Foundation of China (No. 30801487).

\section{Author details}

${ }^{1}$ Department of Gastroenterology, Tangdu Hospital of the Forth Military Medical University, Xi'an, Shanxi 710038, China. ${ }^{2}$ Department of Neurosurgery, Tangdu Hospital of the Forth Military Medical University, Xi'an, Shanxi 710038, China.

Received: 28 August 2013 Accepted: 14 April 2014 Published: 17 April 2014 


\section{References}

1. Kamm KE, Stull JT: The function of myosin and myosin light chain kinase phosphorylation in smooth muscle. Annu Rev Pharmacol Toxicol 1985, 25:593-620.

2. Somlyo AP, Somlyo AV: Signal transduction by G-proteins, rho-kinase and protein phosphatase to smooth muscle and non-muscle myosin II. J Physiol 2000, 522(Pt 2):177-185.

3. Horowitz A, Menice CB, Laporte R, Morgan KG: Mechanisms of smooth muscle contraction. Physiol Rev 1996, 76(4):967-1003.

4. Leinweber B, Parissenti AM, Gallant C, Gangopadhyay SS, Kirwan-Rhude A, Leavis PC, Morgan KG: Regulation of protein kinase $\mathrm{C}$ by the cytoskeletal protein calponin. J Biol Chem 2000, 275(51):40329-40336.

5. Kim HR, Appel S, Vetterkind S, Gangopadhyay SS, Morgan KG: Smooth muscle signalling pathways in health and disease. J Cell Mol Med 2008, 12(6A):2165-2180.

6. Horowitz A, Clement-Chomienne O, Walsh MP, Tao T, Katsuyama H, Morgan KG: Effects of calponin on force generation by single smooth muscle cells. Am J Physiol 1996, 270(5 Pt 2):H1858-H1863.

7. Winder SJ, Walsh MP: Calponin: thin filament-linked regulation of smooth muscle contraction. Cell Signal 1993, 5(6):677-686.

8. Takahashi K, Yoshimoto R, Fuchibe K, Fujishige A, Mitsui-Saito M, Hori M, Ozaki H, Yamamura H, Awata N, Taniguchi S, Katsuki M, Tsuchiya T, Karaki H: Regulation of shortening velocity by calponin in intact contracting smooth muscles. Biochem Biophys Res Commun 2000, 279(1):150-157.

9. Gusev NB: Some properties of caldesmon and calponin and the participation of these proteins in regulation of smooth muscle contraction and cytoskeleton formation. Biochemistry (Mosc) 2001, 66(10):1112-1121.

10. Johnson AL, Goode GD, Mtshali C, Myles EL, Washington B: Protein Kinase C- alpha/betall, delta, and zeta/lambda involvement in ethanol-induced MAPK expression in vascular smooth muscle cells. Cell Mol Biol (Noisy-le-grand) 2007, 53(4):38-44.

11. Hazzalin CA, Mahadevan LC: MAPK-regulated transcription: a continuously variable gene switch? Nat Rev Mol Cell Biol 2002, 3(1):30-40.

12. Hakes DJ, Dixon JE: New vectors for high level expression of recombinant proteins in bacteria. Anal Biochem 1992, 202(2):293-298.

13. Kaptchuk TJ: Acupuncture: theory, efficacy, and practice. Ann Intern Med 2002, 136(5):374-383.

14. Lin X, Liang J, Ren J, Mu F, Zhang M, Chen JD: Electrical stimulation of acupuncture points enhances gastric myoelectrical activity in humans. Am J Gastroenterol 1997, 92(9):1527-1530.

15. Qian $L$, Peters $L J$, Chen JD: Effects of electroacupuncture on gastric migrating myoelectrical complex in dogs. Dig Dis Sci 1999, 44(1):56-62

16. Li Y, Tougas G, Chiverton SG, Hunt RH: The effect of acupuncture on gastrointestinal function and disorders. Am J Gastroenterol 1992, 87(10):1372-1381

17. Yang Q, Huang YX, Li HY, Chen HQ, Qin M, Wang JJ: The mechanism of electroacupuncture at Tsusanli-regulated gastric motility. Chin J Gastroenterol Hepatol 2010, 19(5):462-465.

18. Yamaguchi S, Okada K, Ohsawa H, Miyamoto T, Yosikawa K, Nishijo K: Electro-acupuncture stimulation effects on gastric motility in anesthetized rats. J Soc Neuroveget 1996, 33(1):39-45.

19. Fang ZQ, Shen GM, Xu Y, Li WD, Xu GX: Effect of electroacupuncture stimulation and Ban-Xia-Xie-Xin Decoction on electrogastrography in functional dyspepsia rats. J Anhui TCM Coll 2005, 24:14-16.

20. Chang XR, Yan J, Yi SX, Lin YP, Deng YJ, Zhang H: Effects of electroacupuncture at Zusanli(ST 36) on electric activities of the stomach and brain-gut peptides in rats. Chinese Acupuncture \& Moxibition 2004, 24(2):124-126

21. Balestrini IL, Tsuchida D, Fukuda H, Pappas TN, Takahashi T: Acupuncture accelerates delayed gastrointestinal transit after abdominal surgery in conscious rats. Scand I Gastroenterol 2005, 40(6):734-735.

22. Yan J, Yang ZB, Chang XR, Yi SX, Lin YP, Zhong Y: Expressions of epidermal growth factor receptor signaling substances in gastric mucosal cells influenced by serum derived from rats treated with electroacupuncture at stomach meridian acupoints. Zhong Xi Yi Jie He Xue Bao 2007, 5(3):338-342.

23. Yuan CX, Zhu J, Zhing LX: Gastroscopic observation of the effects of acupuncture on gastric motility. Jiangxi J Chin Trad Med 1985, 16(3):33-34.

24. Ouyang H, Yin J, Wang Z, Pasricha PJ, Chen JD: Electroacupuncture accelerates gastric emptying in association with changes in vagal activity. Am J Physiol Gastrointest Liver Physiol 2002, 282(2):G390-G396.
25. Chen J, Song GQ, Yin J, Koothan T, Chen JD: Electroacupuncture improves impaired gastric motility and slow waves induced by rectal distension in dogs. Am J Physiol Gastrointest Liver Physiol 2008, 295(3):G614-G620.

26. Tatewaki M, Harris M, Uemura K, Ueno T, Hoshino E, Shiotani A, Pappas TN, Takahashi T: Dual effects of acupuncture on gastric motility in conscious rats. Am J Physiol Regul Integr Comp Physiol 2003, 285(4):R862-R872.

27. Chang CS, Chou JW, Ko CW, Wu CY, Chen GH: Cutaneous electrical stimulation of acupuncture points may enhance gastric myoelectrical regularity. Digestion 2002, 66(2):106-111.

28. Iwa M, Nakade Y, Pappas TN, Takahashi T: Electroacupuncture elicits dual effects: stimulation of delayed gastric emptying and inhibition of accelerated colonic transit induced by restraint stress in rats. Dig Dis SCi 2006, 51(8):1493-1500.

29. Tougas G, Yuan LY, Radamaker JW, Chiverton SG, Hunt RH: Effect of acupuncture on gastric acid secretion in healthy male volunteers. Dig Dis Sci 1992, 37(10):1576-1582

30. Imai $\mathrm{K}$, Ariga H, Chen C, Mantyh C, Pappas TN, Takahashi T: Effects of electroacupuncture on gastric motility and heart rate variability in conscious rats. Auton Neurosci 2008, 138(1-2):91-98.

31. Kingston S, Mao L, Yang L, Arora A, Fibuch EE, Wang JQ: Propofol inhibits phosphorylation of N-methyl-D-aspartate receptor NR1 subunits in neurons. Anesthesiology 2006, 104(4):763-769.

32. Jin JP, Walsh MP, Resek ME, McMartin GA: Expression and epitopic conservation of calponin in different smooth muscles and during development. Biochem Cell Biol 1996, 74(2):187-196.

33. Wang $X$, Wu K, Zhang Z, Lan M, Jin J, Fan D: The effect of calponin and caldesmon in regulation of the gastrointestinal motility during pathophysiological adaptation. Chin J Intern Med 2001, 40(7):459-462.

34. Li Y, Je HD, Malek S, Morgan KG: Role of ERK1/2 in uterine contractility and preterm labor in rats. Am J Physiol Regul Integr Comp Physiol 2004, 287(2):R328-R335.

doi:10.1186/1472-6882-14-137

Cite this article as: Yang et al.: Effect of electroacupuncture stimulation at Zusanli acupoint (ST36) on gastric motility: possible through PKC and MAPK signal transduction pathways. BMC Complementary and Alternative Medicine 2014 14:137.

\section{Submit your next manuscript to BioMed Central and take full advantage of:}

- Convenient online submission

- Thorough peer review

- No space constraints or color figure charges

- Immediate publication on acceptance

- Inclusion in PubMed, CAS, Scopus and Google Scholar

- Research which is freely available for redistribution 